\title{
Rancang Bangun Emergency Button Berbasis LORA
}

\author{
Muhammad Fadhiil \\ Febriyan \\ Jurusan Teknik Elektro, \\ Program Studi Teknik \\ Telekomunikasi D IV \\ Politeknik Negeri Sriwijaya \\ Palembang, Indonesia \\ fadhiilmuhammad152@gmail.com
}

\author{
Ibnu Ziad \\ Jurusan Teknik Elektro, \\ Program Studi Teknik \\ Telekomunikasi D IV \\ Politeknik Negeri Sriwijaya \\ Palembang, Indonesia \\ ibnupoltek1@gmail.com
}

\author{
Suroso \\ Jurusan Teknik Elektro, \\ Program Studi Teknik \\ Telekomunikasi D IV \\ Politeknik Negeri Sriwijaya \\ Palembang, Indonesia \\ osorus11@gmail.co
}

\begin{abstract}
There is no denying that wireless communication technology is a very important component of modern society. One aspect of modern society where the application of wireless communication technology has tremendous potential is in an emergency. This is especially true in weak places and cannot be reached at all by cellular signals. A good example would be the application of wireless communication technology to transmit data about the emergency button is mountained. Nowadays in the mountain all those things can happen when the moment, the champion can experience, hurt, or sick in the middle. Therefore, our goal in this study is to develop and test an affordable wireless communication system for the swimming state center when performing applications. The system uses microcontrollers and communication systems that use Arduino and LoRa as Transceivers and Receivers. The system was successfully tested in the field and obtained data with a distance of 1.2 Km.

Keywords - Tombol Darurat, Arduino UNO, LoRa RFM9x, Alaram
\end{abstract}

\section{PENDAHULUAN}

Seiring meningkatnya jumlah pendaki yang mendaki gunung, semakin bayak pula jumlah pendaki yang mengalami kelelahan dan sakit sehingga tidak bisa melanjutkan pendakian, saat pendaki berada diatas gunung pendaki tidak dapat langsung meminta pertolongan karena masih sulit dijangkau oleh sinyal selular sehingga pendaki hanya dapat menunggu pendaki yang lain berpapasan dengan nya, hal tersebut kurang efektif karena cukup berbahaya karena memakan waktu yang cukup lama dan beresiko terhadap pendaki. Dengan menggunakan emergency button ini para pendaki dapat segera mendapatkan pertolongan jika terjadi sesuatu yang tidak dikehendaki.

Pada Emergency Button ini menggunakan Arduino dan LoRa, Arduino dan LoRa ini memiliki beberapa kelebihan diantaranya harganya yang murah, jangkauan sinyal yang cukup jauh[1][2]. Tujuan penelitian yaitu membuat Rancang bangun emergency button sebuah sistem tombol darurat agak pendaki dapat segera mendapatkan pertolongan di checkpoint yang sudah dipasangi alat.

\section{DASAR TEORI}

LoRa merupakan teknologi terbaru dalam bidang jaringan nirkabel dimana pada teknologi ini menggunakan protokol LPWAN. LoRa sangat minim mengkonsumsi daya serta memiliki jarak jangkau mencapai $2 \mathrm{~km}$ lebih jauh jika dibandingkan dengan teknologi xbee dan harganya pun relatif lebih murah sehingga LoRa sangat efisien jika di implementasikan, sama seperti LoRa, Arduino sebagai pengontrol LoRa memiliki jangkauan $2 \mathrm{~km}$ dan harga relative lebih murah sehingga cocok digunakan untuk aktivitas rancang bangun[3].

1. Arduino

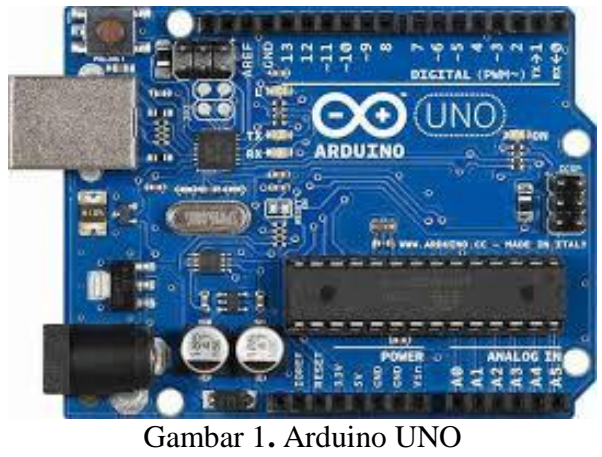

Arduino Uno adalah board mikrokontroler berbasis ATmega328 (datasheet). Memiliki 14 pin input dari output digital dimana 6 pin input tersebut dapat digunakan sebagai output PWM dan 6 pin input analog, $16 \mathrm{MHz}$ osilator kristal, koneksi USB, jack power, ICSP header, dan tombol reset. Untuk menggunakan arduino agar dapat digunakan, cukup hanya menghubungkan Board Arduino Uno ke komputer dengan menggunakan kabel USB atau listrik dengan AC yang-ke adaptor-DC atau baterai untuk menjalankannya[4].

Uno berbeda dengan semua board lainnya dalam hal koneksi USB-to-serial yaitu menggunakan fitur Atmega8U2 yang diprogram sebagai konverter USB- 


\section{Rancang Bangun Emergency Button Berbasis LORA}

to-serial berbeda dengan board sebelumnya yang menggunakan chip FTDI driver USB-to-serial.

\section{LoRa RFM9x}

RFM9x LoRa Module 915MHz adalah modul transceiver jarak jauh yang menggunakan teknologi LoRa untuk menghasilkan komunikasi data yang minim interferensi dan menghemat penggunaan daya[5].

Pengujian LoRa RFM9x mengetahui seberapa jauh dan kualitas jalur yang optimal. Berikut langkahlangkah untuk menghubungkan alat dengan platform :

1. Download library LoRa RFM9x yang ada pada web, lalu install

2. Memonitor serial yang ada pada aplikasi arduino UNO

3. Menentukan Jarak yang akan digunakan

4. Mengukur RSSI Jarak yang digunakan

RSSI dinyatakan dalam $\mathrm{dBm}$ dan merupakan nilai negatif. Semakin dekat dengan 0, maka semakin baik sinyal tersebut sedangkan RSSI minimum adalah $-120 \mathrm{dBm}[6]$.

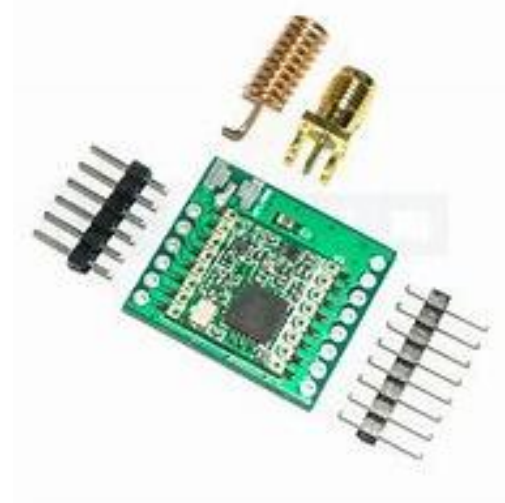

Gambar 2. LoRa RFM9x

3. Antena Omnidirectional

Antena adalah komponen terpenting dalam transmisi. Antena adalah perangkat yang dirancang untuk dapat menerima ataupun memancarkan gelombang elektromaknetik[7].

omnidirectional merupakan jenis antena yang memiliki pancaran atau penerimaan sinyal kesegala arah dengan daya yang sama. Antena omnidirectional biasanya digunakan pada lingkup base station terbatas dan cenderung untuk posisi pelanggan yang melebar[8].

Antena omnidirectional pada rancangan ini menggunakan Antenna SMA Male Omnidirectional Low VSWR.

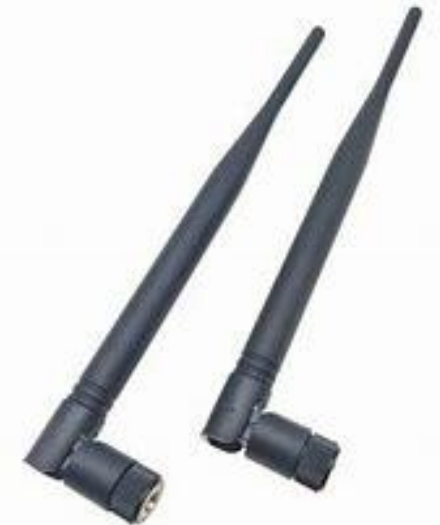

Gambar 3. Antena Omnidirectional

III. METODE PENELITIAN

Tahapan kerangka penelitian dapat dilihat pada gambar berikut.

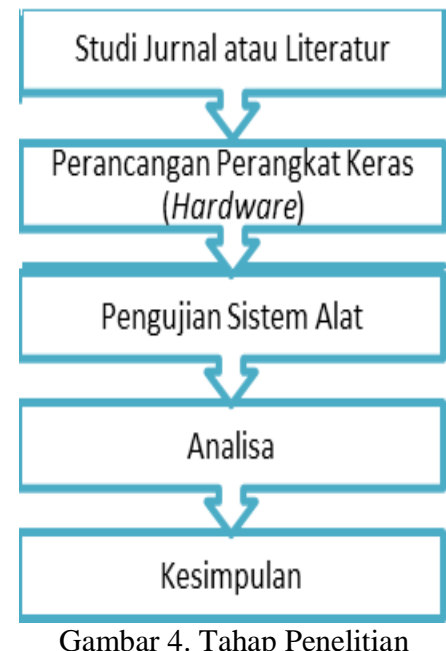

Dari gambar diatas, dapat diketahui bahwa tahap keseluruhan penelitian dimulai dari tahap sebagai berikut.

1. Studi Jurnal atau Literatur

Pada tahap ini penulis membaca dan mempelajari literatur yang relevan sesuai dengan masalah yang akan dibahas. Studi literatur dilakukan dengan cara menelusuri sumber-sumber baik dari jurnal, buku, maupun sumber terpercaya dari internet. Pada tahap ini diketahui masalah pada rancang bangun emergency button, pengujian alat yang tidak mendapatkan hasil yang tidak maksimal. Maka dengan adanya studi literatur diharapkan dapat dilakukan pembaharuan untuk penelitian selanjutnya.

2. Perancangan Perangkat Keras

Pada tahapan ini, penulis akan merancang sesuai dengan kebutuhan alat. Pada sistem ini digunakan LoRa sebagai transceiver dan receiver yang dapat digunakan untuk mengirim sinyal dengan cakupan yang cukup luas, penambahan perangakat keras seperti antena agar memaksimalkan kinerja receiver tersebut. 


\section{Rancang Bangun Emergency Button Berbasis LORA}

Perancangan perangkat keras dapat dilihat pada diagram berikut.

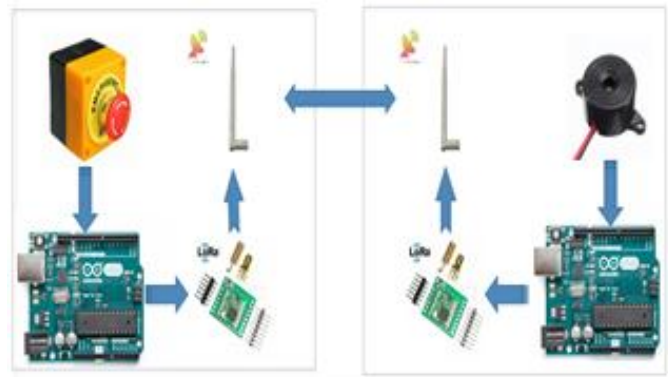

Gambar 5. Perancangan perangkat keras

3. Pengujian Sistem Alat

Pada tahap ini, penulis menguji alat yang sudah terintegrasi untuk mengetahui dan menguji fungsi dari alat yang telah dibangun. Parameter yang akan diujikan berupa nilai RSSI

4. Analisa

Pada bagian ini, penulis melakukan analisa dan pengkajian terhadap alat yang telah selesai dibuat dan diuji.

5. Kesimpulan

Pada tahap ini, penulis merangkum tentang aspek yang ada pada penelitian dan menyimpulkannya secara singkat dan jelas.

\section{HASIL DAN PEMBAHASAN}

A. Perancangan Perangkat keras (Hardware)

Perancangan perangkat keras (hardware) merupakan perancangan alat yang akan dibuat. Pada perancangan alat haruslah diperhatikan dalam dalam pemasangan komponen komponen yang dibutukan untuk membuat alat. Dengan memperhatikan karakteristik pada komponen dapat mengurangi terjadinya kesalahan dalam perancangan.

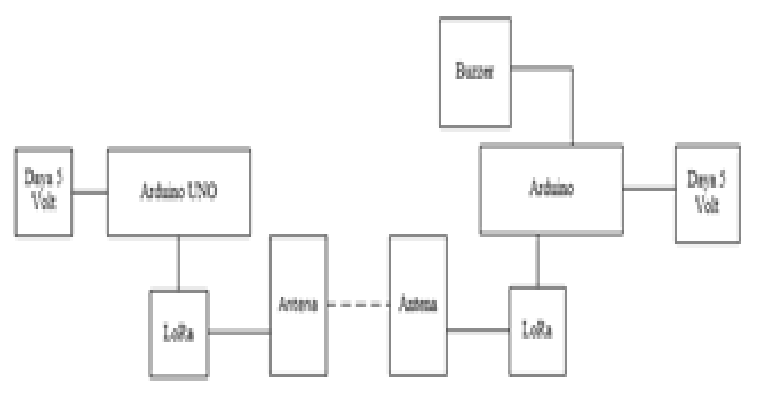

Gambar 6. Blok Diagram Perancangan Perangkat Keras (Hardware)

1. Perancangan Perangkat Keras Keseluruhan

Tampilan alat sistem keamanan sepeda motor secara otomatis telah dirancang sesuai dengan blok diagram perancangan perangkat keras (hardware) yang mana pada alat tersebut berupa transmitter yang diberikan dan receiver yang diberikan buzzer dan LCD.

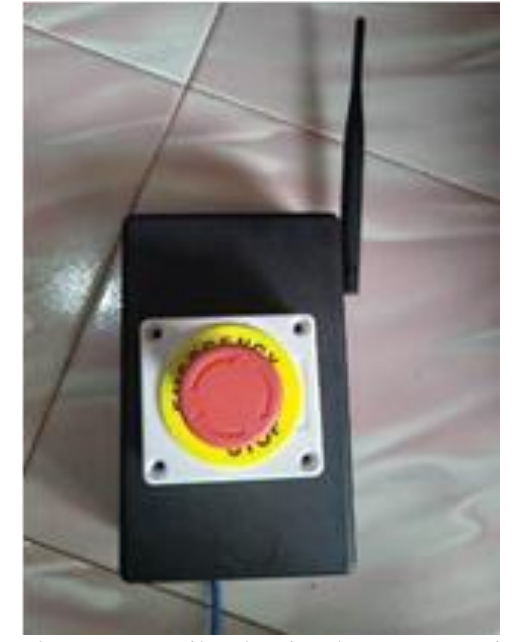

Gambar 7. Tampilan bagian luar Transmitter

Pada gambar diatas adalah hasil pemasangan perangkat yang telah dihubungkan dan Arduino sebagai pengontrolnya dan button sebagai inputnya.

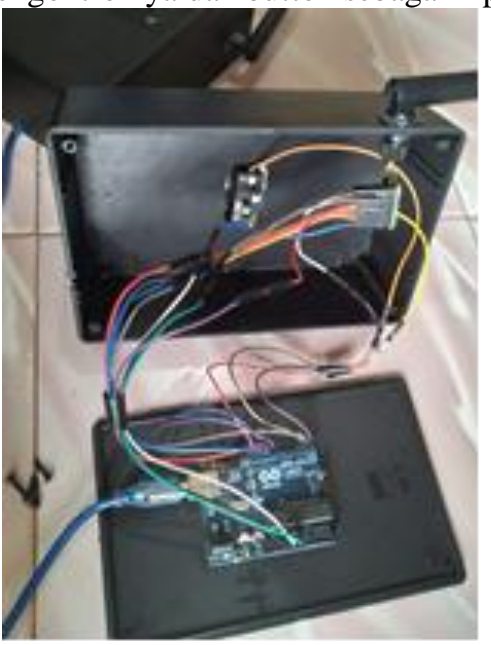

Gambar 8. Tampilan bagian dalam Transmitter

Pada gambar diatas adalah pemasangan perangkat Arduino UNO, LoRa RFM9x dan button

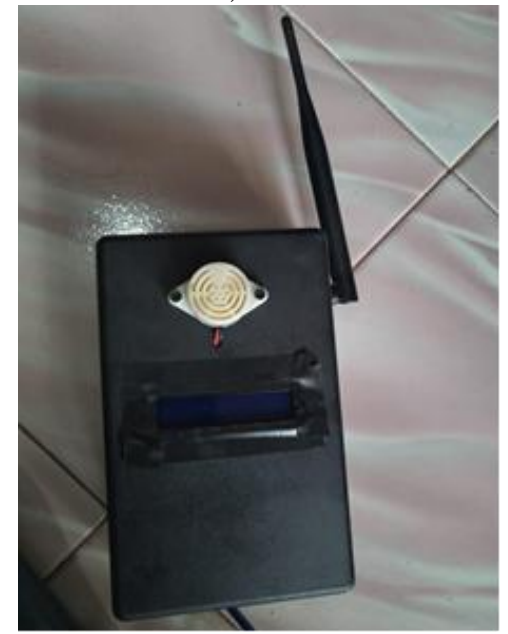

Gambar 9. Tampilan bagina luar receiver 


\section{Rancang Bangun Emergency Button Berbasis LORA}

Pada gambar diatas adalah tampilan receiver yang telah dipasangkan buzzer dan LCD sebagai outputnya

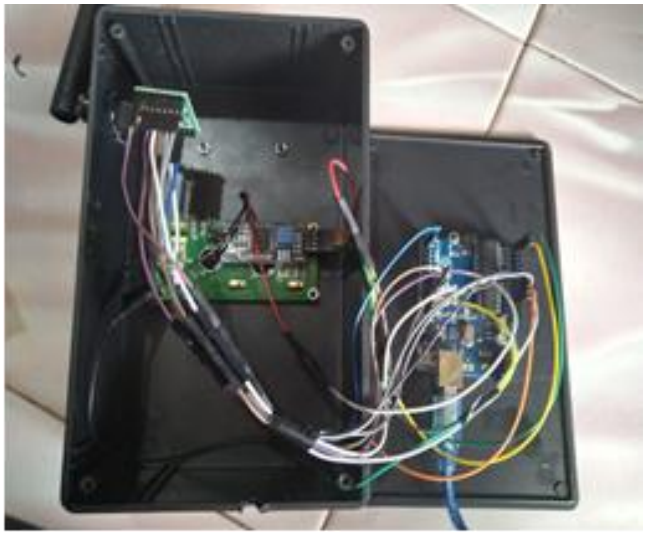

Gambar 10. Tampilan bagian dalam receiver

Pada gambar diatas adalah hasil perangkat yang telah dipasangkan buzzer dan LCD

\section{B. Pengujian}

Pada tahap pengujian, perangkat keras dihubungkan ke komputer yang telah diinstall software arduino. Dalam pengujian yang dilakukan pada hari sabtu tanggal 1 agustus 2020, pukul 17:12 WIB di kota palembang diperoleh hasil sebagai berikut.

Tabel 1. Pengujian Jarak dan RSSI

\begin{tabular}{|c|c|}
\hline Jarak $(\mathrm{m})$ & RSSI $(\mathrm{dBm})$ \\
\hline 300 & -88 \\
\hline 600 & -91 \\
\hline 900 & -98 \\
\hline 1200 & No Reply \\
\hline
\end{tabular}

Berdasarkan hasil percobaan table 1 diatas dengan melakukan 4 pengujian, pada setiap jarak semakin jauh maka akan semakin besar besar juga nilai RSSI.

\section{SIMPULAN}

Dari hasil pengujian perangkat dapat bekerja dengan baik, meskipun belum mencapai jarak maksimal karena terhalang oleh gedung dan perumahan warga yang lain, jarak pengukuran mempengaruhi nilai RSSI, semakin besar nilai RSSI maka akan semakin kualitas sinyal yang diterima.

\section{DAFTAR PUSTAKA}

[1] N.S. Mazloum, O. Edfors, Performance analysis and energy optimization of wake-up receiver schemes for wireless low-power applications, IEEE Trans. Wireless Commun. 13 (12) (2014) 7050- 7061 .

[2] B. Martinez, M. Monton, I. Vilajosana, J. Prades, The power of models: modeling power consumption for iot devices, IEEE Sens. J. 15 (10) (2015) 5777-5789.

[3] LoRa, "A technical overview of LoRCa® and LoRaWANTM.," LoRa Allience, 2014.
[4] C. Goursaud, J.-M. Gorce, Dedicated networks for iot: PHY/MAC state of the art and challenges, EAI Endorsed Transactions on Internet of Things (2015).

[5] LoraWANTM, Specification v1.0, Lora Alliance, Inc. 2400 Camino Ramon, Suite 375 San Ramon, CA 94583 (2015), 2015, LoRa Alliance, Technical Report.

[6] Aoudia, F. A. et al., 2017. Long-short range communication network leveraging LoRa ${ }^{\mathrm{TM}}$ and wake-up. Microprocessors and Microsystems.

[7] Agustin, A.; Y, Jiazi: W, Mark T. A Study Of LoRa : Long Range and Low Power Networke For the Internet Of Things. Ecole Polytechique Router de Saclay.

[8] Springer, A.; Gugler, W.; Huemer, M.; Reind, L.; Ruppel, C. Spread Spectrum Communications Using Chirp Signals. Proceeding IEEE/AFCEA Information system 